\title{
La construcción del lenguaje gráfico en el diseño de moda y la transformación del cuerpo femenino
}

\section{Moretti, Nancy de P.}

Resumen:

El presente artículo aborda el tema de Diseño de Moda analizando el proceso de codificación de la expresión gráfica, en el sentido de entender cómo sucedió el modo de hacer, crear y producir vestimentas a lo largo de la historia de la moda.

También, trata de identificar el proceso acumulativo de transformaciones del cuerpo orgánico natural a través de las representaciones mediadas por los diseños hasta transformarse en cuerpo de moda, es decir, en Diseño de Moda.

Palabras clave:

Diseño - Cuerpo - Moda - Arte -

Cuadernos del Centro de Estudios de Diseño y Comunicación N76

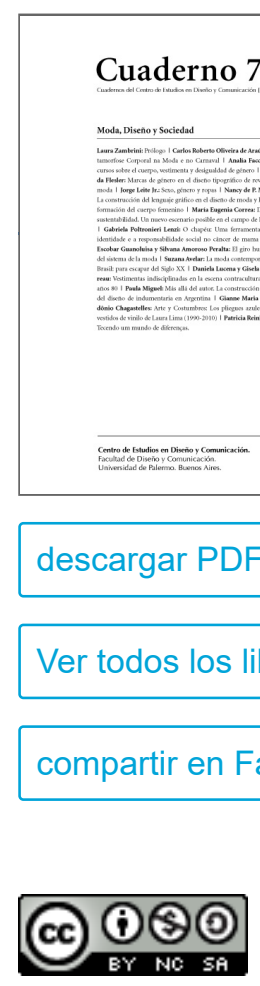

Esta obra está bajo una Licencia Creative Commons Atribución-NoComercialCompartirlgual 4.0 Internacional

Transformaciones Corporales.

$\left.{ }^{*}\right)$ Doutora pelo Instituto de Artes - UNICAMP - Universidade Estadual de Campinas - SP. Tese - Corpo Antípoda A representação do corpo humano no Desenho de Moda: Uma abordagem semiótica. Doutorado Sanduíche no Centro de Estudos de Comunicação e Sociedade da Universidade do Minho - Portugal 2013/2014. Mestre em Moda, Cultura e Arte pelo Centro Universitário Senac Santo Amaro, SP 2009. Experiência docente em Moda desde 2003 e em Arte educação desde 1999. Docente na FATEC Faculdade de Tecnologia de São Paulo, UNISAL Centro Universitário Salesiano de São Paulo e FAAL Faculdade de Administração e Arte de Limeira.

Introducción

Este artículo se remonta inicialmente al siglo XIV, cuando los trajes de fiestas eran diseñados por los artistas de la corte. Por ejemplo, en la corte francesa, el propio Luis XIII orientaba a los artistas en una representación prospectiva para la creación de sus propios trajes. Esto supuso el comienzo de la confección de ropas a través de recursos de expresiones gráficas, legado éste de las habilidades de los pintores reales de la corte, quienes estaban acostumbrados a copiar de modo fiel a los personajes importantes de las cortes (Ver Figura 1). 
A lo largo de ese siglo, la moda fue adquiriendo características extremadamente rígidas e inconfortables que obligaban a los individuos a mantener una postura altiva y jerárquica (Pires, 2005, p. 44). En ese sentido, la manipulación de la imagen corporal y la estructura del discurso del cuerpo vestido tienden a evidenciar las características más atractivas del cuerpo que son elegidas según los valores estéticos compartidos por un cierto grupo social o época (Castilho e Galvao, 2002, p. 69) (Ver Figura 2).

A partir del siglo XV, las ilustraciones hechas en grabaciones de metal o madera ya podían ser producidas en grandes cantidades. La divulgación de lo que serían los modelos idealizados como referentes para el correcto y actualizado modo de vestir, consolidaron el futuro del mercado de la moda. La difusión de las imágenes ilustradas provocó cambios de comportamiento social, sirviendo como referencia e interfiriendo en el estilo de vida de las personas. Hasta hoy, es imposible separarlos en el entendimiento del proceso de formación de grupos de decisión formadores de opinión, que emiten las señales de las novedades que serán divulgadas y seguidas por la sociedad de consumo.

Un hecho importante con relación a la difusión de comportamientos del siglo XVII que está fuertemente introducido en la cultura femenina actual son los tacones. En términos técnicos específicos, los tacones promueven una elongación artificial del cuerpo. Este estiramiento aparentemente inofensivo causa muchas veces compresión de los pies y malestar, de forma que su uso tiene como prioridad apenas la estética y la elegancia. Entre los elementos introducidos en la moda del siglo XVII, nos interesan dos en especial. El primero de ellos son los zapatos con tacones altos. Utilizado inicialmente por individuos de ambos sexos, ese elemento que restringe los movimientos y dificulta el movimiento, se convirtió a lo largo del tiempo, debido a las atribuciones sociales dadas a los hombres y mujeres, en un objeto exclusivo del vestuario femenino (Pires, 2005, p. 49).

La reproductividad técnica de diseños de vestuario y accesorios presentes en periódicos y revistas como forma de inducir hábitos culturales considerados saludables, eran una forma de expandir el mercado textil y cosmético, y de persuadir sobre la personalidad femenina sumisa a las costumbres y los buenos modales impuestos por la sociedad patriarcal. La primera publicación de imagen de la moda fue hecha en 1672 por Wenceslaus Hollar (1607-1677) en la revista francesa "Le Mercure Galant" (Ver Figuras 3 y 4). Durante siglos los artistas se han inspirado en ropas y tejidos. Los ilustradores de moda retratan las tendencias del momento, divulgando no apenas ropas, sino también sus criadores. En la primera mitad del siglo XVII, los diseños detallados y descriptivos de Wenceslaus Hollar dieron inicio a la ilustración de moda (Morris, 2007, p. 82). Sus diseños tenían detalles técnicos pues hacía muchos años diseñaba no sólo trajes, sino también las costumbres, mapas geográficos, diseños arquitectónicos, entre otros. A pesar de haber sido el primer artista citado, por sus imágenes direccionadas para el público femenino, es poco probable que Hollar haya tenido relación directa con casas de modistas en Londres.

Felizmente, había un grupo de artistas que eran codiciosos en saber sobre modas y costumbres, y en sus peregrinaciones grabaron sus impresiones haciendo imágenes en madera (Mackrell, 1997). En 1810 fue comercializada la primera muñeca de papel, también conocida como "Paper Doll". Se trataba de un conjunto de piezas de papel sin cuerpo. Apenas el cuello y la cabeza podían ser vestidos de diversas maneras. De esa forma, se percibe una reproductividad del diseño de moda alcanzando varias clases sociales y edades diferentes. El diseño de moda difundido al universo lúdico infantil era un reflejo de la moda adulta consolidada en 
los parámetros corporales de esa época. En las vestimentas de papel, la mayoría de las veces ya estaban incorporados los brazos y los pies (Ver Figura 5).

En ese frágil vínculo con la representación del cuerpo abstraído de la muñeca, encontramos indicios de un cuerpo que se aleja del real biológico debido a la abstracción de sus partes, es decir, un cuerpo vestido construido a partir de un apagón de partes fundamentales del cuerpo orgánico humano. Los orígenes del diseño de moda le deben a estas muñecas el inicio de una reflexión cognitiva e imaginativa del vestir en un cuerpo abstraído. El acto de fragmentar el cuerpo, de vaciarlo de órganos y su volumetría, de sus dimensiones, de disminuirlo y pasar a tratarlo como suporte, es muy parecido al proceso de estilización del diseño de moda.

En el año 1858, Charles Frederick Worth (1825-1898), pionero de la Alta Costura se destacó por el estilo innovador de las ropas que creaba. Empeñado en imponer ese estilo, no se limitó a desarrollar los modelos que sus clientes pedían sino que montó una Maison renovando la forma de presentación de las ropas.

Históricamente, fue Worth el primer costurero en exponer a una clientela particularmente seleccionada, sus modelos presentados a través de maniquís vivos. La forma diferenciada y articulada de Worth agregó alto valor comercial a sus productos. El costurero, después de siglos de renegación subalterna, se convirtió en un artista moderno, aquel cuya ley imperativa es la innovación (Lipovetsky, 1989). Worth se impuso como artista porque interfirió en la estructura de la ropa y creó modelos inéditos, provocando cambios en las formas, tejidos y accesorios. El costurero adoptó un procedimiento semejante al de un pintor que transforma cualquier objeto en obra de arte por el hecho de marcarlo con su firma: la diferencia es que él actúa de manera más vistosa porque la estructura específica del trabajo, le proporciona tal posibilidad; además, se exprime de manera más abierta porque la menor legitimidad de su arte lo intimida a responder a cuestiones impensadas por la más elevada legitimidad de la pintura (Bourdieu, 2006).

Los diseños de Worth eran gráficamente bien detallados (Ver Figura 6) y se percibe una relación muy fuerte entre el cuerpo originalmente biológico adaptado para el cuerpo vestido, pues las caderas resaltadas hacían parte de casi todas las vestimentas, formando el cuerpo en silueta de "S" (Ver Figura 7). Inclusive, en las propagandas de ropa íntima, donde el cuerpo aparece desnudo, el diseño de la silueta era tendencioso a formar una "S". Una especie de corrección al cuerpo biológico. La representación gráfica de ese cuerpo en formato S es un indicio más de las deformidades causadas al cuerpo orgánico. Hay una erotización en el plano imaginario de esos artistas que envergan el dorso elevando las caderas, despreciando completamente la estructura del cuerpo orgánico. Sería imposible sin el artificio de las caderas y adaptaciones de crinolinas crear una envergadura lumbar como la propuesta. El cuerpo creado en la imaginación de esa época exigía robustez, delicadeza y redondeo de las formas en la cadera. Worth contribuyó de forma bastante expresiva en la difusión de esa modalidad artística, es decir, en el arte de diseñar la ropa usando el cuerpo como soporte. Antes de Worth, los costureros o sastres eran vistos como artesanos rutineros y normalmente no opinaban sobre los modelos. La profesión de costurero o sastre tradicionalmente era transmitida de padre a hijo, sin embargo, la tensión causada por la lógica del sistema productivo provocó una división técnica en el trabajo artesanal de la vestimenta, separando la mayoría de los costureros, los cuales pasaron a trabajar como operarios y los artistas se volvieron técnicos a través de las primeras escuelas de artes y oficios. Bajo la iniciativa de Worth, la moda llegó a la era moderna; se convirtió en una empresa de creación y también de espectáculo publicitario. Después, decenas de casas organizadas sobre los mismos principios aparecieron: en la exposición de 1900, veinte casas de Alta Costura estuvieron presentes, entre las cuales, Worth, Rouff (fundada en 1884), Paquin (1891), Callot Soeurs 
(1896), Doucet, que más tarde emplearía a Poiret, abrió sus puertas en 1880, Lanvin en 1909, Chanel y Patou en 1919 (Lipovetsky, 1989).

Las ilustraciones de moda se volvieron frecuentes en las noticias y revistas de Europa, Rusia y América del Norte. A mediados de 1855, la economía industrial creció y los atelier de lujos comenzaron a tener en sus establecimientos, creadores de moda que realizaban diseños individuales para cada cliente. Por toda Europa se expandieron las Artes Gráficas, las escuelas de Artes y Oficios, uniendo pedagógicamente el acto creativo, las técnicas productivas y reproductivas con la lógica industrial. Anterior a Gigson Girl, los cuerpos femeninos gráficamente representados no tenían alteraciones morfológicas explícitas, se asimilaban con el cuerpo humano normal sin muchas alteraciones estéticas, restringiéndose al perfeccionismo académico realista y la mayoría de las veces, venían asociados a los modos de costumbres de la época. Por tanto, un nuevo concepto de ilustración aparece con Charles Dana Gibson (1897-1944), iniciado en 1890, que propone en sus diseños una mujer creada e idealizada en su imaginario, una mujer inalcanzable (Ver Figuras 8 y 9). Esta dimensión imaginaria alcanzada y mediada por la facilidad con que el diseño tiende a crear circunstancias imposibles de ser vistas dentro del plano real de la vida humana. Las mujeres vieron en Gibson Girls un arquetipo de femineidad asociada a una personalidad de libertad. Las ilustraciones de las Gibson Girls provocaban un cambio de valores, pues las mujeres comenzaron a copiar los peinados y las poses. Los objetivos eran de alguna forma parecerse a las Gibson Girls. Las ilustraciones no sólo documentaban, sino que también dictaban la moda. La famosa Gibson Girl, figura del ideal americano creada por Charles Dana, inspiró tendencias de moda para mujeres que protestaban por el sufragio femenino -largas faldas y blusas bordadas de cuello alto, con corbata, bufanda o camisón completando el visual (Bryant, 2012). Es posible identificar las transformaciones en representaciones de la imagen del cuerpo vestido.

La potencialidad onírica del imaginario a nivel figurativo, creó un cuerpo modelado en patrones anatómicos imposibles de ser alcanzados en cuerpos orgánicos, de carne, huesos, músculos y órganos, la única manera de expresión era a través de groseras aproximaciones. El cuerpo usado en el diseño de moda estimuló, a través de su potencialidad, el deseo inconsciente de ser un otro o de atraer el deseo del otro.

El ser humano posee una naturaleza pro eminentemente social: su comportamiento, su personalidad, su modo de pensar y sentir sus necesidades, inclusive de decorarse, comienzan a ser explicables cuando lo percibimos susceptible a la existencia real o imaginaria de otros individuos. El otro es estímulo y ocasión de respuesta. La respuesta del otro en relación al propio individuo (o si, o yo) determina sus acciones y sus sentimientos (Castilho, Martins y Marcelo, 2008). El cuerpo físico de Gibson Girl consistía en un cuerpo delgado, alto, con cintura extremadamente fina, con un rostro sereno, pero no sumiso. Las ilustraciones insinuaban una mujer femenina, que también podía dedicarse al deporte y al trabajo. No era vista únicamente en las revistas de moda como Time, Life y Harper's Bazaar, sino en anuncios de jabones y otros productos femeninos en una escala en masa. Muchas mujeres respondían a los anuncios de corsés para adquirir la curva en $\mathrm{S}$ del mítico personaje.

La joven Gibson personificada en el diseño consiguió algo mágico: la admiración de las mujeres y el deseo de los hombres. Las Gibson Girls generaron un modelo propagado como referencia para las mujeres de la época. La nueva mujer idealizada en la era industrial, liberada de sus funciones domésticas, hasta entonces estrictamente amarrada al tedio de las funciones repetitivas del hogar (Ver Figura 10). 
En el inicio del siglo XIX, como consecuencia, aparecieron los métodos de corte y costura para la enseñanza de la profesión de costurero(a). La gran mayoría de los diseñadores de moda trabajaba también como arquitectos o floristas de estampas para papel de paredes o estamparía de tejidos. La Art Nouveau o Arte Floreal influenció a los ilustradores durante el paso del siglo XIX hacia el siglo XX (Ver Figura 11).

Las primeras décadas del siglo XX fueron doradas para la ilustración de la moda. Las ilustraciones hechas por artistas como Sonia Delaunay aparecieron en la Vogue Francesa, elevando las ilustraciones a un nivel artístico. Las formas expresivas de la pintura moderna queriendo librarse del fardo de la reproducción realista de la Arte Académica o fotográfica, marcharon hacia la ruptura de los contornos rígidos de la figura humana, de los objetos de la naturaleza muerta y los paisajes, siguiendo una geometría rigurosa que no representaba nada, a no ser a sí misma. Estas diversidades expresivas influenciaron a los nuevos estilistas que se referenciaban en la cultura de la época y no querían aislarse de los movimientos estéticos en curso (Ver Figura 12). Paul Poiret (Ver Figura 13) fue uno de los creadores más importantes de la época, considerado por algunos autores como el primer estilista. Utilizaba arte, imaginación, originalidad y sobretodo el color; sin embargo, sus creaciones la mayoría de las veces eran diseñadas por otros artistas como Erté y Georges Barbier, entre otros.

Los diseños sugerían siluetas esbeltas, casi sin senos, con poca cintura y en tejidos leves. El cuerpo vestido pasó a determinar qué tipo de mujer habitaría el imaginario de esa época. La idealización de ese cuerpo casi sin formas se ajusta a la practicidad de una nueva personalidad femenina (Ver Figuras 14 y 15).

La ligereza de las ropas y la liberación del afinamiento de las cinturas reafirmadas en las décadas anteriores dieron lugar a la figura larga y delgada. Analizando anatómicamente el cuerpo propuesto por las ilustraciones de Poiret, se percibe un encogimiento de los senos y una geometrización del cuerpo. También era sugerido un estiramiento del cuello en los diseños para incentivar el uso de bufandas. El diseño de moda comenzó a ser alargado y estirado en ese período, donde la mujer delgada sin formas entró en evidencia (Ver Figura 16). En Erté, no es el cuerpo femenino que está vestido (vestidos, capas, crinolinas, frac, alas, velos, joyas y mil bagatelas barrocas, cuyo efecto es inagotable, tal como la invención), es el vestuario que es prolongado como el cuerpo (de ningún modo rellenado por él, pues las figuras de Erté, con razón irrealistas, son indiferentes a sus ropas interiores: todo se inventa, se sustituye, se desenvuelve poéticamente a la superficie). Tal era la función de la silueta en Erté: poner y proponer un objeto (un concepto, una forma) que sea unitaria, una mezcla indisoluble de cuerpo y vestuario, de modo que no se pueda ni desvestir el cuerpo ni abstraer el vestuario: Mujer enteramente socializada por su traje, obstinadamente corporizado por el contorno de la mujer (Barthes, 2009). La mujer con aire de niña frágil era la misma mujer que comenzaba a trabajar y practicar deportes. No podemos olvidar que en ese período estaba ocurriendo la Segunda Guerra Mundial. La vestimenta femenina pasó por un proceso de fragmentación y practicidad debido a los trabajos externos que forzadamente las viudas tuvieron que agregar a los quehaceres domésticos para proveer sus casas. Por otro lado, no podemos desconsiderar el proceso de sistematización de la producción de la moda en que el diseño pasó a ser un medio de conducción de estrategias de marketing o para la venta de la reserva de tejidos acumulados y con el alto costo de la fotografía, la ilustración realista continuó hasta la década de los años 20 (Ver Figura 17). En esta época, crecieron los cursos de diseños de moda, direccionados para la creación de estampas. El entrenamiento y perfeccionamiento en desenvolvimiento de especialistas de la representación siguieron la sedimentación de la división técnica del trabajo. El diseño se convirtió en moneda común entre un pensamiento que se codifica en lenguaje y las acciones de naturaleza ejecutiva, por ejemplo con las modelistas y costureras. La naturaleza de esta codificación fue el centro de un proceso que se ramificó y multiplicó ganando un status dentro de la operación 
del sistema de moda. El diseño ganó el mercado minorista, expuesto en tiendas de tejidos y catálogos de reventas para confecciones.

En la década de los años 1930 y 1940, la silueta andrógina desapareció y las formas femeninas fueron revalorizadas. En las manos de ilustradores como Carl Erikson y René Bouët Willaumez, los diseños ganaron pinceladas suaves, texturas, líneas y curvas. El perfeccionamiento del lenguaje expresivo, a través del diseño, se hizo gracias a la percepción y sensibilidad de los ilustradores que imprimieron un carácter personal desde una concepción artística más libre, reflexionando en la libertad expresiva del artista convencional formado en las academias de Bellas Artes, en donde la originalidad y la innovación siempre fueron la garantía del éxito. Estos saltos hacia la individualización, elevaron el lenguaje del diseño vinculado a la lógica productiva y cerrada del sistema de la moda, rompiendo con aquellos patrones rígidos que fueron cristalizándose cuando se convirtieron en códigos establecidos entre varios diseñadores e ilustradores de la moda. Las representaciones de los trajes eran a través de la observación de modelos vivos. De alguna forma, el vínculo con el cuerpo orgánico pasó a ser la referencia para un entrenamiento en las proporciones y en la precisión y complejidad de la anatomía humana. Este proceso de formaciones de carácter académico dentro de las Bellas Artes perduró con la convicción que las deformaciones posteriores, podrían obtener una madurez del artista en la búsqueda de su propio lenguaje expresivo. Existía la preocupación en diseñar una atmósfera de elegancia y femineidad con trazos rápidos. Esa habilidad y técnica proporcionó un mayor dominio sobre el conocimiento y la representación del cuerpo (Figura 18 y 19).

René fue influenciado por Eric, pero aceleró su impronta personal con el uso de colores, escotillas rápidas y sombras vigorosas. Sus ilustraciones tenían un profundo sentido de estilo y dominaron las páginas de la Vogue por muchos años (Jones, 2005). El ascenso de la fotografía provocó un declive en la ilustración de moda en la década de 1950. Los anuncios de ropas y tejidos se fragmentaron entre el cine y la televisión; las revistas de moda en la dé- cada siguiente, los años 60 , prácticamente extinguieron a las ilustraciones. La multiplicidad y difusión rápida de las imágenes de carácter realista de estos medios alteraron la percepción y la cognición en las representaciones del cuerpo por los ilustradores (Ver Figura 20).

El surgimiento de la imagen técnica fue determinante, desafiando a las artes plásticas como elemento de ruptura y liberación para nuevas osadías expresivas de las imágenes, creadas por la sensibilidad del cuerpo que proponían los ilustradores de moda. Entre los sobrevivientes, Antonio López se destacó en las décadas del 60, 70 y 80 . Con respecto a la corporeidad de los años 70 , Pires (2005, p. 73 ) escribió:

Es partir de esa década que la influencia directa de la moda sobre o comportamiento -principalmente el comportamiento femenino- deja, en un corto período de tiempo, marcas evidentes e incontestables en el cuerpo: la anorexia y la bulimia. El culto a la delgadez, que tuvo inicio en los años anteriores, pasa a ser altamente explorado por los estilistas, que colocan en la pasarela modelos extremamente delgadas.

Su imaginación fértil lo llevó a experimentar todos los estilos posibles, usando inúmeros materiales y técnicas. A cada estación él experimentaba una nueva técnica de ilustración, descartando los estilos que ya se habían convertido en populares y eran seguidos por otros. (Morris, 2007, p. 89) (Ver Figura 21)

Los alumnos de los cursos de moda tenían esos artistas como referencia. Había dos segmentos relacionados al diseño de moda. Por un lado, el sector textil que formaba a sus alumnos para la creación de tejidos, prendas, 
estampas y por el otro, los ilustradores que trabajaban en revistas, tiendas de tejido y talleres. La fuerte influencia de la fotografía en los editoriales de moda en los años 70 , hizo al diseño de moda aparecer de una forma diferente: como diseño técnico. Este pasó a ser la otra fase en la proliferación de la imagen técnica. La creatividad y la imaginación de los ilustradores se direccionaron hacia otros vértices del hacer artístico. La producción se volvería más exigente con la eficiencia de la reproductibilidad de diseños, que tenían que ser más objetivos y menos ambiguos, según los rigores de la precisión. La propuesta era ayudar a la identificación de detalles, pues esas revistas eran direccionadas para personas que querían costurar en casa. Además, de la foto de la ropa eran introducidos moldes en el medio, o al final de la revista, pequeños diseños técnicos y moldes listos (Ver Figura 22).

En la década de los años 80, las ilustraciones resurgieron con sus estilos característicos pero sin embargo, las exactitudes de las fotografías ya suplían todas las necesidades de representación. Por lo tanto, la ilustración de moda resurgió, ya no para demostrar las ideas y creaciones, sino para sugerir conceptos. El diseño se distanció significativamente de la representación figurativa, reafirmándose en aspectos más abstractos y conceptuales, propios de un sistema de la moda que necesitaba del alargamiento del cuerpo en proporciones irreales. Sea en la anchura, como en la altura, esto ocurrió en el proceso creativo a través de la elasticidad de las formas. La concepción de diseño se movió en dirección hacia una diversidad de posibilidades, de elecciones orientadas por una mujer idealizada, por un perfil a ser construido y por un cuerpo a ser vestido. El carácter elástico se apropió entonces de ese cuerpo vestido, potenciado por la forma y la amplitud de los significados. Cargado de simbolismos sobre la mujer de la década de los años 80 , las ilustraciones retrataban croquis con hombros exageradamente anchos, rostros estilizados dando cierta ambigüedad entre lo masculino y lo femenino. La silueta geométrica en el cuerpo vestido, surgió principalmente, a través de las hombreras que aproximaban los hombros con ángulos rectos. Hubo un acercamiento corporal entre las ropas femeninas y masculinas. La sastrería se centró principalmente en el perfil de la mujer independiente.

Las poses eran representadas de manera teatral en las revistas de moda, donde también encontrábamos los moldes de las ropas presentadas. Esas revistas de moda direccionadas a las mujeres que querían costurar sus propias ropas, hicieron ganar fuerza nuevamente al diseño ilustrativo y técnico. Además de las formas geometrales de la silueta de la década de los años 80 , renacieron las tribus urbanas, y en este sentido, no podemos olvidar el registro gráfico sobre el cuerpo a través del tatuaje (Ver Figura 23).

Según Pires (2005, p. 79):

El tatuaje gana cada vez más espacio y comienza a ser acompañado por el piercing. Traspasar el cuerpo envuelve más que interferir con la piel - envuelve interferir con la carne, con la sangre y, en algunos casos, con los cartílagos.

Los modelos para la noche exhibían exageraciones y ostentaciones principalmente en los accesorios. La década de 1990, quedó marcada por el desarrollo cada vez mayor del diseño vectorizado. Las ilustraciones ganaron calidad de impresión y recursos expresivos de tridimensionalidad (Ver Figuras 24 y 25).

Después de la década de 1990, hubo una mezcla de técnicas manuales y computarizadas, principalmente en las Facultades de Moda de Brasil. Los croquis muy delgados y largos se convirtieron prácticamente en un código 
insertado actualmente en el diseño de moda, aunque no fueron los únicos requisitos para que un diseño tuviese estilo y se encuadrase en la codificación de la moda. En palabras de Morris:

Imágenes generadas por computador y la tecnología digital de los años 90 significaron un boom para la ilustración. Hubo ilustradores que crearon peque- ñas subculturas ávidamente adoptadas por el Mundo de la moda: Brooks produjo folletos generados por computador para el club Pushca, y Rounthwaite creó una colección con jóvenes de las calles de Nueva York en un Macintosh. Sus anuncios para Levis fueron proyectados en enormes letreros en las laterales de los edificios - una verdadera señal de que la ilustración estaba de vuelta a la ciudad. Además, ilustraciones de las supermodelos con ropas de alta costura como las de David Downton se esparcieron por todos los periódicos y revistas (Morris, 2007, p. 92)

Actualmente, el diseño de moda persigue trazos más libres y poses más osadas. Ya no es común encontrar en los almacenes de tejido un estilista que haga los diseños como era costumbre años atrás. Por otro lado, el interés creciente por los cursos de moda hizo que el dibujo de moda se volviera una práctica expresiva y de creación artística entre los futuros diseñadores. Tanto el diseño con técnicas manuales o el diseño hecho por computador exigen habilidad y creatividad artística para configurarse en, lo que podemos llamar, de diseño de estilo o diseño de moda. En un principio, lo que parecía ser el mapa de ideas del diseñador, está siendo cada vez más objeto de estudios científicos y académicos (Ver Figura 26).

Desde la perspectiva creativa del estilista de moda y sus trazos creadores de una colección, podemos pensar en un cuerpo que nace vestido. Ocurre entonces una ocultación que no esconde al cuerpo desnudo, pero que lo recrea sin huesos ni órganos cubiertos por un vestido imaginario que se abstrae de las dimensiones y las proporciones de un ser humano y le confieren una elasticidad que permite alargamientos y desconoce limitación. Podemos reconocer en los trazos, que se trata de una sugerencia del cuerpo humano, aunque en su correlación está en oposición y por eso, se trata de un cuerpo mutable, insinuado en las formas. Esos hechos son importantes para que entendamos que el diseño de moda fue instituido, en un modelo de cuerpo idealizado. Alargar y afinar la figura, son las primeras deformaciones, sin embargo, el estilista crea la ropa con toda su intensidad expresiva y de libertad, sin los límites formales de la anatomía del cuerpo natural como guía. Esa iniciativa alcanza los extremos de la potencialidad imaginativa a través del cuerpo vestido. Desde la perspectiva del creador de moda, el cuerpo antípoda se fortalece y afirma por la proporcionalidad del cuerpo delgado, relacionado a la elegancia y estilo. En el abordaje semiótico observamos que es un cuerpo que pertenece al sistema de la moda y por lo tanto, se comunica y es reconocido por un público específico.

\section{Consideraciones finales}

Las modificaciones corporales, en contextualización histórica de la sociedad, a lo largo de las décadas causaron influencias significativas en el diseño de moda. Los diseños se adaptaron a los biotipos femeninos de cada época y también interfirieron en el imaginario de las personas dictando tendencias, tanto en las modificaciones corporales, como en las vestimentas. Las representaciones gráficas del cuerpo femenino en cuadros, anuncios publicitarios, revistas de modas, pasarelas y desfiles, pasaron por muchas transformaciones. No podemos olvidar que el diseño de moda es un diseño específico creado dentro del universo de la moda para la moda. Cuando un ilustrador compone gráficamente una ilustración, está insertando parte de su idea. La imagen mental formada en una concepción de diseño, está cargada de subjetividades, proyectando un cuerpo que pueda ser deseado. Ese cuerpo, que al principio tenía forma humana, se transforma en una imagen desde los recursos 
artísticos del diseño. Esta multiplicación del cuerpo como imagen tiene una potencialidad de inducción de la conducta humana en quererse parecer a una imagen; y confiere al cuerpo orgánico un estatus de reconocimiento afectivo y de pertenencia a los segmentos sociales, formando tribus urbanas reconocibles e identificables, construyendo significados existenciales de equilibrio psicológico y de satisfacción personal del ser humano. Esto hace de la Moda algo más que simplemente una lógica de mercadología. El cuerpo usado como base en el diseño de moda, parte de la referencia del cuerpo biológico, pero este objeto de referencial procesado por la mente del estilista, se transforma en un cuerpo técnicamente de moda. Incluso, si en algún momento la referencia haya sido el cuerpo humano desnudo en su manifestación natural y fisiológica, como cuerpo orgánico, acaba transformándose en un cuerpo técnicamente de moda, más alargado y delgado, de naturaleza especifica de la lógica productiva del sistema de la moda. El objetivo final es la vestimenta, o sea, el cuerpo vestido como una creación utilitaria dentro del sistema de la moda. De esa forma, puede ocurrir la eliminación de partes del cuerpo o incluso, una fusión con la vestimenta que muestra un cuerpo muchas veces usando trazos de materiales como pastel, acuarela, marcadores, maniquí, dando al cuerpo orgánico una nueva forma rediseñada a través del proceso creativo e imaginativo del estilista. Este cuerpo alterado morfológicamente con técnicas artísticas, simplificado, alargado y re-significado es el resultado de un proceso muy conocido en el campo de la moda: la estilización. Para demostrar este concepto de diseño de estilo, o el estilo estilizado, fue necesario demostrar cómo el diseño de moda se constituyó y se estableció a lo largo del proceso de formación de los agentes y del propio sistema de la moda. Fue preciso para esta finalidad, describir históricamente la dinámica evolutiva de la expresión gráfica en el propio sistema.

Hay un alejamiento de la realidad del cuerpo fisiológico y el diseño figurativo resulta esquemático y simplificado. El sistema de la moda está estructurado por una comunicación de naturaleza global de las redes telemáticas y se convierte en una matriz comunicacional de la sociedad del espectáculo. Ella es la fuerza que mueve y alimenta, presentando cuerpo virtuales hiper-reales y desmaterializados en diferentes medios de comunicación. Las modelos en las pasarelas se presentan como cuerpos extremadamente delgados y alargados, diferentes de la mayoría de la población mundial y, sin embargo, son a través de las imágenes de ellas que se dictan las tendencias de moda. Lo mismo acontece en las revistas de moda, donde los cuerpos trabajados con sistemas computarizados se tornan hiper-reales. Las cuestiones de las transformaciones corpóreas, también están ligadas a lo que Baudrillard (1991) llama Hiper-realidad e imaginario. Estamos insertos en un universo paralelo construido bajo las imágenes ópticas, donde las cosas son más seductoras que la realidad. Las personas quieren tener cuerpos hiper-reales, ignorando aspectos morfológicos naturales. No hay límites para la perfección en el imaginario. Las industrias invierten en un imaginario colectivo, concebido de cuerpos hiper-reales inalcanzables, generando necesidad de consumo de productos y servicios. El diseño de moda es determinado por esas influencias que direccionan las nuevas creaciones o las nuevas tendencias en los cuerpos vestidos, entendiendo el cuerpo, ya no con su naturalidad original que existe a priori, pero sí dentro de un complejo sistema comunicacional inserto en la lógica productiva, social, económica y culturalmente dominante.

\section{Bibliografía}

Barbier, G. (1924). Revista La Gazette du Bon Ton. Disponible en: http://www.flickr.com/ photos/gatochy/2751791188. Accesado en: 03/2016.

Barthes, R. (2009). O Óbvio e o Obtuso. Lisboa: Edições 70 Ltda. 
Baudrillard, J. (1991). Simulacros e Simulação. Lisboa: Relógios d’Água.

Bourdieu, P. (2006). A produção da crença: contribuição para uma economia dos bens simbólicos. Porto Alegre: Zouk, $3^{\mathrm{a}}$ edição.

Brooks, J. (2013). Fendi Moda Espalhe Fuente. Disponible en: http://www.folioart.co.uk/ illustration/folio/artists/illustrator/jason-brooks/. Accesado en: 03/2016.

. (2015). Anjo Fierce - Hed Kandi. Disponible en: http://www.folioart.co.uk/

illustration/folio/artists/illustrator/jason-brooks/. Accesado en: 03/2016.

Bryant, M. W. (2012). Desenho de Moda: Técnica para Estilistas. São Paulo: SENAC.

Castilho, K. e Galvão, D. (2002). A Moda do corpo, o Corpo da Moda. São Paulo: Esfera. , K. e Martins, M. (2008). Discursos da moda semiótica, design e corpo. São Paulo: Anhembi Morumbi, $2^{\mathrm{a}}$ edição.

Delaunay, S. (1926). Revista Vogue. Disponible en: http://onthisdayinfashion.com/?p=10256. Accesado en: 03/2016.

Erté (Romain de Tirtoff) (1917). "Fleur Parmis les Fleurs: diseño de Erté para capa de Harper's Bazaar". Disponible en: http://www.metmuseum.org/art/collection/search/343008. Accesado en: 03/2016.

(Romain de Tirtoff) (1978). "Symphony in Black" Disponible en: http://www. artdecotours.com, en 4/06/2011. Accesado en: 03/2016.

Fanny Little. Publicado en Londres, por S. y J. Fuller: una pieza de cartón, con una cabeza móvil, y 7 cuerpos con ropas y accesorios, 1810. Disponible en: http://www.theriaults.com. Accesado en: 07/2012.

Gibson, C. D. (1895). Ladies' Home Journal. Disponible en: http://historymatters.gmu. edu/d/6783/. Accesado en: 03/2016.

Habit d'Hyuer. Trajes femeninos disenhados por Wenceslaus Hollar publicados en la revista Le Mercure Glant, 1678. Disponible en: http://www.gutenberg.org/files. Accesado en: 07/2015.

Jones, S. J. (2005). Fhasion Desing - manual do estilista. São Paulo: Cosac Naiy.

Kumagai, K. (1988). Fashion Illustrations 2 (Capa del libro). Japão: Graphic-Sha.

Lipovetsky, G. (1989). O Império do Efêmero: a moda e seu destino nas sociedades modernas. São Paulo: Cia das Letras.

Mackrell, A. (1997). An illustrated history of fashion: 500 years of fashion illustration. London: B.T. Batsford.

Morris, B. (2007). Fashion Illustrator - Manual do ilustrador de moda. São Paulo: Cosac Naify. 
Pires, B. F. (2005). O Corpo como Suporte da Arte. São Paulo: SENAC.

Abstract: This article analyzes Fashion Design from the process of coding graphic expression. The aim is to understand how the way of making, creating and producing clothes along to history of fashion. Also, it is about identifying the acumulative process of transformations of organic body through the representations mediated by the designs until becoming a fashionable body, that is, in Fashion Design.

Keywords: Design - Body - Fashion - Art - Transformation Bodies

Resumo: Este artigo analisa o design de moda desde o processo de codificação da expressão gráfica. O objetivo é entender como o modo de fazer, criar e produzir as roupas se deu ao longo da história da moda. Além disso, trata-se de identificar o processo acumulativo de transformações do corpo orgânico e natural através das representações mediadas pelos desenhos até se tornar um corpo da moda, ou seja, no Design de Moda.

Palavras-chave: Design - Corpo - Moda - Arte - Transformações Corporais.

[Las traducciones de los abstracts fueron supervisadas por el autor de cada artículo]

La construcción del lenguaje gráfico en el diseño de moda y la transformación del cuerpo femenino fue publicado de la página 73 a página87 en Cuadernos del Centro de Estudios de Diseño y Comunicación №76 